\title{
El Progreso Agrícola: uma Cooperativa no Pampa Bonaerense ${ }^{1}$
}

\author{
El Progreso Agrícola: a cooperative in Buenos Aires' pampa
}

\section{Alba Cristina Couto dos Santos Salatino}

1 Este trabalho teve sua primeira versão apresentada na Mesa de trabalho 32 Los inmigrantes y su esencial aporte al cooperativismo entrerriano durante la consolidación institucional y el despegue económico de las entidades desde mediados del S.XX: um balance prometedor; a qual integrou o evento, Jornadas. Un siglo de migraciones en la Argentina Contemporánea: $1914-$ 2014, realizado em setembro de 2016, no Instituto Gino Germani, Buenos Aires - CABA, Argentina. Agradeço a contribuição dos participantes, sobretudo, as reflexões da Profa. Dra. Celia Gladys Lopez (Universidad Autónoma de Entre Ríos).

2 Doutoranda do Programa de Pós-Graduação em História da Universidade do Vale do Rio dos Sinos -UNISINOS. Bolsista CNPq.

\section{Resumo}

0 presente trabalho analisa alguns momentos da trajetória da cooperativa El Progreso Agrícola de Pigüé (Bs As), entre 1900 e 1920, considerando, sobretudo, sua constituição a partir de imigrantes franceses. Com base nos estudos de transnacionalidade, investigamos desde a bibliografia à imprensa local ou regional, em acervos da província de Buenos Aires. Nossa análise tem por preocupação captar as práticas cooperativas desses imigrantes, relacionando-as com as experiências cooperativas do país de origem. Dessa maneira, procuramos identificar a doutrina inspiradora da prática cooperativa, naquele contexto, ao final do século XIX. Acreditamos que as associações cooperativas são também um meio de intercâmbio cultural, do associado com o seu próprio meio social, rural ou urbano. Elas também são lugares passíveis de transformação e de manutenção da doutrina cooperativa. Nesse sentido, a El Progresso Agrícola, como uma das primeiras expressões de organização cooperativa argentina, teve um desenvolvimento promissor, em meados do século $X X$, que inspirou e motivou a criação de novas cooperativas.

\section{Palavras-chave}

Cooperativismo; doutrina cooperativa; Buenos Aires; imigração francesa; transnacionalidade.

\begin{abstract}
This study analyzes some moments along the path of the cooperative El Progreso Agrícola de Pigüé between 1900 and 1920, considering above all its formation by French immigrants. Based on the studies of the transnationality, we investigate from bibliography up to local or regional press, in archives of the province of Buenos Aires. Our analysis aims to capture the cooperatives practices of those immigrants, in view of their experience with cooperatives in their country of origin. We seek to reason about the doctrines, which inspired these practices, in that context, at the end of the 19th century. We believe that cooperative associations are also a mean to cultural exchange between the affiliated and its own social environment, either rural or urban. Transformation and preservation of the cooperative doctrine can happen within these associations. In this sense, the El Progreso Agrícola as one of the first expressions of the Argentinean cooperative organization and its promising development in mid-twentieth century, which inspired and motivated the creation of new cooperatives.
\end{abstract}

\section{Keywords}

Cooperativism. Cooperative doctrine. Buenos Aires. French immigration. Transnationality. 


\section{PRIMEIRAS PALAVRAS}

O trabalho apresentado aqui vem ao encontro da necessidade de dialogar sobre o tema do cooperativismo rural, que ganhou maior visibilidade na historiografia nas últimas décadas do século XX. Os estudos estão concentrados, majoritariamente, entre o período de 1930-1970, evidenciando que ainda há diferentes perguntas a serem feitas ao passado das instituições cooperativas da Argentina. A bibliografia estudada, a qual tivemos acesso, analisa o plano econômico do sistema cooperativo rural, cujas abordagens discutem a relação entre as políticas e o desenvolvimento do sistema agrário. Reflexões importantes que nos mostram um papel significativo do cooperativismo na engrenagem econômica regional e nacional. Outras abordagens contemplam a discussão e efetivação dos princípios cooperativos e a própria participação do associado, como eixos norteadores da ação coletiva que é um empreendimento cooperativo.

O nosso estudo está centrado na cooperativa El Progreso Agrícola de Pigüé: Sociedade Cooperativa Mútua de Seguros Agrícolas y Anezos Ltda, com o objetivo de refletir alguns momentos de sua trajetória. Pensamos a sua constituição a partir da iniciativa dos imigrantes franceses, considerando que tenha ocorrido a ressignificação, em terras americanas, dos velhos saberes e tradições, sobretudo aqueles relacionados à cooperação, que podem ser transportados e adaptados de um lugar para o outro.

Baseados na ideia de transanacionalidade, privilegiamos as influências de experiências vividas no passado ou conhecidas mediante a intercâmbios da vida cotidiana, sem necessariamente buscar pontos físicos e geográficos contínuos. Nesse sentido, a transnacionalidade é entendida como "circulação cultural", nesse caso, da práxis cooperativista. Conforme ressaltam os intelectuais da área, o conceito está apoiado numa constante reformulação de ideias, de propostas e de práticas culturais que transitam de um contexto para outro. (WEINSTEIN, 2013, grifo nosso).

Embora o cooperativismo tenha sua origem no contexto europeu do século XIX, a sua prática é passível de transformação em acordo com o grupo que constitui a cooperativa e do contexto onde está inserido. Assim, procuramos compreender a iniciativa desses imigrantes franceses, relacionando-a com a emergência de problemas econômicos que lhes afetava, ao lado das motivações de desenvolvimento local, isto é, tornar a colônia próspera. Para analisar as práticas da cooperativa e sua inserção na região, temos utilizado os periódicos locais e a bibliografia disponível, sobre essa imigração (de franceses para zona rural) e o cooperativismo argentino.

Empreendemos uma investigação em arquivos ${ }^{3}$ da província de Buenos Aires, inclusive na cidade onde, ainda hoje, está localizado a matriz da cooperativa El Progreso Agrícola, no Museo y Archivo de la Ciudad de Pigüé. Nesses acervos, encontramos a ata de fundação da cooperativa e diversas notícias publicadas, entre 1900-1920, no periódico El Reflector e no La Prensa. As notícias variam desde assuntos sobre homenagens e aniversários da instituição a balanços, prestação de contas e comunicados públicos das assembleias, ou seja, publicações feitas pela própria instituição e de outros abordando sobre ela. Nosso aporte teórico- metodológico ${ }^{4}$ está apoiado nos estudos sobre a imprensa e os eventos de comemoração (como frutos memorialísticos de uma pessoa, de um grupo, de uma data,

3 Archivo General de la Nación - AGN (Cidade Autônoma de Buenos Aires- CABA); Sociedad Rural Argentina - SRA (CABA); Biblioteca Utopía (CABA), Biblioteca Central da UMdP (Bs As).

4 Os estudos a que nos referimos são estes: sobre eventos comemorativos e evocações de representações sociais por intermédio desses eventos, CATROGA, F. Os passos do homem como restolho do tempo. Memória e fim do fim da história. Coimbra: Almedina, 2009. Sobre a imprensa e o uso dela na pesquisa histórica, CAPELATO, M. H. Imprensa e História do Brasil $\left(2^{a}\right.$ ed.). São Paulo: Contexto / EDUSP, 1988; SAMARA, E. M., \& TUPY, I. S. História \& documento. Metodologia e pesquisa. Belo Horizonte: Autêntica, 2007; MENDELEVICH, P. Las revistas. Cuadernos de Historia Popular Argentina, pp. 1-20, (1982-1986). Esclarecemos que as referências completas em notas de rodapé, não constarão ao final do texto. 
etc.), os quais não são expressões neutras do passado. Por isso, nossa interpretação procurou ficar mais atenta a essas vozes do passado, observando o seu lugar de fala e para quem fala.

Em geral, a El Progreso Agrícola é mencionada em diversos trabalhos sobre o cooperativismo, reconhecendo-a como a primeira expressão desse movimento socioeconômico no pais. No entanto, ainda não encontramos um trabalho que nos conte sobre a sua história, os desdobramentos e implicações da cooperativa na região, estando ela em funcionamento desde 1898. Em vista da produção intelectual significativa do tema do cooperativismo na Argentina, arriscamos a pensar que ausência de estudos específicos sobre a El Agrícola diz respeito à falta de consenso entre os pesquisadores acerca do segmento em que a cooperativa se enquadraria. Seria ela uma cooperativa agrária ou uma cooperativa rural?

Dante Osvaldo Cracogna enfatizou, no seu livro Cooperativismo agrário argentino, que a "El Progreso Agrícola pode ser considerada uma cooperativa de caráter rural, mas não propriamente agrária, devido a sua política de atuação" (CRACOGNA, 1968, p. 43). Essa interpretação possui seguidores ${ }^{5}$ e divide opiniões. A afırmação de Cracogna não nos parece a mais adequada, quando acessamos o estatuto da cooperativa. Embora não seja nossa intenção entrar nessa discussão do país vizinho, ao considerar os dados do censo nacional de 1895 e de 1914, verificamos que a agricultura aparece como a principal atividade econômica da cidade de Pigüé e de Gral Saavedra, o departamento a qual faz parte. Tais dados caracterizam a cidade de Pigüé majoritariamente agrária, cujas atividades econômicas exercidas eram ligadas à terra e à criação de animais. Ela está situada ao Sudoeste da província de Buenos Aires, na região que compreende o Pampa argentino.

Como veremos a seguir, a cooperativa não praticava eminentemente a produção agrícola, ou seja, não é uma cooperativa destinada à produção. Mas sua atuação é direcionada a esse público, como um instrumento de garantia da colheita e do trabalho. Portanto, no nosso entendimento, não se trata somente de uma cooperativa no meio rural, pois suas atividades foram diversificadas de acordo com as necessidades do seu principal foco de atendimento: o agricultor ou pequeno produtor.

De acordo com Mario Yuri Izquierdo (1972), a El Progreso Agrícola pode ser considerada a primeira cooperativa agrícola da Argentina, devido ao fato de atuar na zona agrária e por contar com sócios de perfis tipicamente rurais e agrários. Essa postura nos parece mais apropriada. A verificação conceitual nos dá alicerces para pensar dessa maneira. Conforme Leonice Aparecida Alves esclarece em sua tese, o adjetivo rural refere-se prioritariamente ao contexto ambiental e cultural da vida no campo, enquanto que o agrário se relaciona ao aspecto econômico e produtivo do espaço ${ }^{6}$. Diante disso, veremos que a El Agrícola compõe e atua nesse espaço geográfico, isto é, contribui com a vida econômica e cultural dos seus associados, a partir do seu caráter associativo; ao mesmo tempo, ela assegura o bem social mediante os seguros agrícolas oferecidos.

Para além dessa questão, ainda se discute na historiografia argentina, o fato de ser uma cooperativa especializada em seguros, o que foi apontado por alguns autores com desconfiança. Teria a EI

5 Até mesmo entre aqueles que não consideram a El Agrícola como cooperativa agrária, há posicionamentos diferentes em relação ao início do seguimento cooperativo agrário na Argentina. Alfonso Vargas Sanchez, por exemplo, defende que não houve na Argentina uma cooperativa agrária até 1904, momento em que se criou na localidade de Junín (Bs As) a Liga Agrícola Ganadera. Ver mais; VARGAS, Alfonso. El cooperativismo agrário argentino. REVESCO, Revista de Estudios Cooperativos, $\mathrm{n}$. 63, p. 185-204, 1997. Disponível em: <https://dialnet.unirioja.es/descarga/articulo/1148464.pdf>. Acesso em: 17/05/2017. Daniel Plotinski, considera a primeira cooperativa agrícola a Primera Sociedad Agrícola Israelita Argentina (que mudou o nome mais tarde para Sociedad Agrícola Lucienville Cooperativa Limitada). Ela foi fundada no ano de 1900, por colonos judeus, na provincia de Entre Ríos. Disponível em:< http://bit.ly/2yJzKm9>. Acesso em: 26/04/2016.

6 Para saber mais ver, ALVES, Leonice Aparecida de Fátima. Estado, educação e modernização agrária: o papel da escola de engenharia de Porto Alegre (RS: 1889-1930). Tese (Doutorado em História) - Programa de Pós-Graduação em História, Universidade do Vale do Rio dos Sinos, São Leopoldo, 2008, pp 1-17; 68. 
Progresso Agrícola caráter cooperativo? Essa discussão e a própria história da cooperativa nos levou a formular algumas questões: o que precisa para ser uma cooperativa? A El Progresso Agrícola teve inspiração de algum modelo cooperativo para atuar? Qual? Será aquele dos Pioneiros de Rochdale? Nesse sentido, nossos argumentos se concentram nos princípios cooperativos e, por consequência, na finalidade de uma cooperativa.

Os Pioneiros de Rochdale é o nome dado ao grupo de trabalhadores responsáveis pela criação da Sociedade Equitativa dos Pioneiros de Rochdale, no condado de Lancashire, Inglaterra, em 1843/1844 ${ }^{7}$. Essa Sociedade trabalhava baseada na ajuda mútua e na cooperação entre seus associados, cujo fim se destinava a abastecer o seu pequeno mercado e comercializar os quatro produtos disponíveis: açúcar, farinha de trigo, farinha de aveia, e manteiga. Em meio às tensões socioeconômicas, daquele contexto, essa foi a solução encontrada pelos trabalhadores para amenizar os prejuízos que estavam tendo com o avanço do liberalismo e das más condições de trabalho nas fábricas. Por muito tempo, foi difundido que esta teria sido a primeira cooperativa. Atualmente, se sabe que, talvez, seu grande mérito está em ter normatizado os princípios da cooperação em estatuto ${ }^{8}$, pois outras cooperativas foram forjadas em paralelo a essa de consumo, em outros países, que inspiraram da mesma maneira tal prática cooperativa.

Nesse caso, destacamos os precursores sociais do associativismo na França, país de origem dos imigrantes que queremos conhecer mais: Conde de Saint-Simon, Pierre Proudhom, Charles Fourier, Michel-Marie Derrion, Louis Blanc e Philippe Buchez. Todos eles destacaram a associação de pessoas como forma de "ação emancipadora" da classe trabalhadora. Em vista desses teóricos franceses que, inclusive implementaram experiências associativas e cooperativas, enfatizamos, em acordo com José Odelso Schneider, que os Pioneiros constituíram apenas o núcleo originário da doutrina cooperativa, a qual foi sendo sistematizada posteriormente, para manter os princípios essenciais e adaptar outros, conforme as peculiaridades regionais e culturais. (SCHNEIDER, 2012, p. 255- 256).

De acordo com Marluza Marques Harres (2007, p. 371), "dificilmente poderíamos falar de um modelo universal de cooperativismo, mesmo que há um fundo comum, de humanismo social, entre as diversas experiências. Existe uma pluralidade de estruturas e métodos nos países onde o cooperativismo nasceu". A expansão do cooperativismo não foi homogênea, nem na Europa. Cooperativas foram sendo criadas, inclusive, sem o conhecimento de ouras ou não se reconheciam como parte de um mesmo movimento, pois diferentes segmentos foram sendo criados: consumo, crédito e produção, no meio urbano ou rural. A pluralidade também vem como resposta das correntes intelectuais socialistas do século XIX.

Chamamos a atenção para o movimento cristão católico-social que, desde 1831, ganhava terreno na Europa, preconizando moderado intervencionismo estatal. 0 modelo de cooperação difundido por esse movimento teve representantes na Alemanha, França, Áustria e Bélgica, que viam o cooperativismo com simpatia e consideravam-no uma possível solução para os problemas econômicos que

7 Rochdale foi um centro fabril de indústrias têxteis. Além disso, desde 1840, a região sofria com más safras, constituindo um grupo associativo diverso, do campo e da cidade. É comum associar essa experiência ao pensamento de Robert Owen, socialista inglês bastante atuante na primeira metade do século XIX, visto como o mais notável idealizador da cooperação.

8 Isso não quer dizer que outras cooperativas não possuíssem estatutos ou normas. Pode ser simplesmente pelo acesso as fontes, tendo sido o estatuto dos Pioneiros de Rochdale o primeiro a ser conhecido. Ou, por ter sido uma experiência que foi amplamente divulgada na Europa, pelos meios de comunicação e congressos; enfim, muitos podem ser os motivos. Mas o que achamos importante ressaltar é o fato de a Aliança Cooperativa Internacional - ACl, criada em 1895, ter adotado os princípios dessa experiência, o que a tornou oficialmente reconhecida. 
surgiam. ${ }^{9}$ Os princípios das cooperativas confessionais também foram publicados, no Journal des Sciences Morales et Potiques (17/12/1831), e "apresentaram bastante semelhança aos princípios dos Pioneiros de Rochdale" (PINHO, 1965, p. 49).

$\mathrm{Na}$ Alemanha, por exemplo, as cooperativas de crédito criaram suas próprias linhas ideológicas ou doutrinárias, ao mesmo tempo da configuração de sua prática. Friedrich Wilhelm Raiffeisen se destaca nesse modelo, ao criar o Clube do Pão, em 1846, na comarca de Weyerbusch, com a finalidade de oferecer o forno e a padaria de forma comunitária. Ele fundou outras associações alguns anos depois, a Associação de Socorro Mútuo para Agricultores, em 1849; e a Associação Caritativa de Heddesdorf, no ano de 1854. Raiffeisen está entre os expoentes do cooperativismo baseado na solidariedade cristã. 0 modelo de caixas de crédito rurais (tipo Raiffesen, como são reconhecidas), desenvolvidas a partir da Associação de Heddesdorf, inspirou sem dúvidas novas experiências.

Na França, a primeira cooperativa foi forjada por Michel-Marie Derrion, discípulo de Saint Simon, no segmento do consumo. Le Commerce Véridique et Social atuou em Lyon, entre 1835-1838, com grande impacto social para aquela época de tensões e conflitos sociais ${ }^{10}$. As tentativas de uma sociedade cooperativa só cresceram, mas começaram a ter maior estabilidade na França, a partir de 1870. As cooperativas de crédito católicas encontraram terreno fértil nesse país, a partir das ideias precursoras e, também, inspiradas na experiência alemã. Em 1885, foi criado um banco cooperativo de crédito fundado por Carlos Rayneri.

De toda forma, pretendeu-se mostrar que temos, na Europa do século XIX, uma forma de cooperação que respondia aos anseios e necessidades dos trabalhadores daquele período, estabelecendo uma nova forma de pensar a relação de trabalho. Dessa maneira, não há uma única origem do cooperativismo, mas podemos destacar países como, a Inglaterra, a França e a Alemanha.

Para alguns autores, dentre os setores que compõem o cooperativismo, o que cumpre a missão dos princípios doutrinários é o setor agrário, isto é, ele desenvolve com maior competência o trabalho cooperativo para fins sociais e econômicos simultaneamente. Contudo, é importante que frisemos nosso entendimento quanto às associações cooperativas. Percebemos a cooperação por meio de cooperativas um recurso de intercâmbio cultural entre o associado-cooperativa e cooperativa-sociedade, para mais que o seu fim financeiro. A doutrina cooperativa se faz nesse conjunto de associação-empresa, que se esforça economicamente para cobrir as necessidades financeiras de seus membros, privilegiando a ajuda mútua entre eles e seguindo uma racionalidade de eficiência social.

\section{A EMIGRAÇÃO FRANCESA E A COLÔNIA DE PIGÜÉ}

A imigração francesa na Argentina ocupa um lugar importante, como um modelo cultural e intelectual das classes dirigentes, no século XIX. A França foi o segundo país a investir capital financeiro na Argentina, somente atrás da Grã-Bretanha, e ocupou a terceira posição quantitativa no fluxo imigratório,

9 Essas cooperativas de crédito fundam-se em: a) no princípio cristão de "amor ao próximo"; b) admitem auxílio de caráter filantrópico, embora prefiram o princípio de "self-help"; c) dão grande importância à formação moral dos associados, os quais têm responsabilidade solidária e ilimitada, quanto às obrigações contraídas pela cooperativa; d) concedem créditos a longo prazo; f) preconizam a organização de um banco central para atender às necessidades das diversas cooperativas de crédito; g) não remuneram os dirigentes da sociedade; g) não distribuem retorno (PINHO, 1965, p. 45).

10 O economista Denis Bayon tem publicado alguns estudos, nos últimos anos, afirmando ser essa experiência a primeira cooperativa constituída aos moldes de princípios socialistas e democráticos. Tal posicionamento questiona, portanto, o título de pioneira da cooperativa inglesa de Rochdale. Ver mais em; Bayon, Denis. Michel-Marie Derrion, pionnier coopératif. Economie \& Humanisme, n.354-octobre, 2000. Disponível em: http://www.revue-economie-et-humanisme.eu/bdf/docs/r54_derrionpionniercoop_ratif.pdf. Acesso em: 12/10/2016. 
ficando atrás dos italianos e espanhóis - sendo esses o primeiro e o segundo lugar respectivamente. "Os franceses selaram sua marca de maneira geral na cultura argentina, na forma de falar, atuar, pensar e na moda" (FERNÁNDEZ, 1999, p. 9).

Na década de 1990, Hernán Otero alertou para a escassa escrita na história sobre a imigração francesa na Argentina, sobretudo aquelas que ocorreram na segunda metade do século XIX (OTERO, 1999). Para ele, o que havia eram histórias episódicas e pouco aprofundadas. De fato, nos deparamos com pouca historiografia sobre essa imigração, tendo o referido autor como principal expoente de consulta e diálogo. Inspiramo-nos no seu artigo, para falar da emigração francesa a partir do seu lugar de origem por acreditar que, dessa forma, compreendemos melhor seus deslocamentos, representações sociais e práticas culturais que foram construídas no lugar de destino.

Houve um grande fluxo interno na França, cujas zonas regionais ${ }^{11}$ são de fronteiras. 0 autor destaca duas características básicas da emigração: 1) a concentração em departamentos, considerando que a emigração não foi em todo o país; 2) a especialização da mão-de-obra, de acordo com o país de origem. A partir de 1880, essa configuração muda substancialmente com as novas zonas de emigração, principalmente na região sudoeste do país, destacando os habitantes de Aveyron - que tiveram como destino os Estados Unidos da América e a Argentina - e de Saboia. Dessas duas localidades, os emigrados tiveram como destino a Argentina. Após essa década, a geografia da emigração voltou a se estabilizar e incorporou mais uma zona que adquirirá importância no fluxo emigratório da França, a Bretanha.

O aumento emigratório identificado entre 1870-1880 na França se explica pelas transformações econômicas da Europa ${ }^{12}$ e a ampliação das zonas emigratórias. Uma revolução técnica colocou a agricultura como principal atividade econômica do mundo ocidental. Portanto, a crise nesse setor - com queda de preço, de produtos e da terra, bem como, o empobrecimento de pequenos e médios proprietários - causaria profundos prejuízos. As crises agrícolas constituíram, segundo Otero, um mecanismo regulador que afetou diretamente no cotidiano dos pequenos proprietários rurais. "Os exemplos mais significativos são: a crise da videira, entre 1853-1858, e a mais devastadora da filoxera, entre 1870-1890. Essa última afetou países como Languedoc, o País Basco e Aveyron" (OTERO, 1999, p. 132).

Os franceses que vieram ao sul da América, especialmente ao Rio da Prata, são em grande medida do oeste francês com traços significativos de regiões focalizadas. Uma influência importante nesses deslocamentos foi a especialização regional, como já dissemos anteriormente. Baseada em fatores culturais, tais especializações orientaram os destinos como, por exemplo, a região do sudoeste francês, essencialmente católica e mais latina, dirigiu-se para a América do Sul. Aveyron está nessa região com uma população majoritariamente rural, por isso, consideramos essas características culturais para compreender os valores e ações praticadas pelos imigrantes que se instalaram em Pigüé.

A Argentina foi um dos países do mundo que mais recebeu imigrantes franceses. Ao final do século XIX, devemos considerar os atrativos que o país oferecia. Em primeiro lugar, as passagens subsidiadas pelo governo argentino, entre 1881-1895; em segundo lugar, o "agente de imigração", cujo principal

11 São quatro zonas especializadas na emigração ultramarina no século XIX: 1) a fronteira com os Pirineus (com os departamentos de Pirineus Atlânticos - incluindo a região basca francesa -, Altos Pirineus e Pirineus Orientais; 2) a bacia superior do Rio Garonne e a bacia inferior do Ródano; 3) as bacias do Reno e do Mosela, e; 4) no norte da França, a bacia de Paris e o departamento de Sena Marítimo (OTERO, 1999, p.128).

12 Antes da unificação da Itália e Alemanha se constituía uma nova Europa, marcando essa década como um divisor de águas. A unificação desses países colocava em risco as fronteiras francesas. Na guerra franco-prussiana, todos os estados europeus declararam-se neutros e se configurou como a primeira guerra de massas. Os alemães do sul se aliaram e se uniram contra a França. A derrota na guerra franco-prussiana, a crise econômica e social, numa população essencialmente rural, contribuiu para esse aumento. 
objetivo era fazer propaganda do país no exterior; ${ }^{13}$ e em terceiro lugar, as possibilidades econômicas que geravam expectativas positivas nos futuros imigrantes, frente à crise europeia - como o acesso à propriedade da terra. Esses três itens formam um conjunto de elementos significativos para atrair estrangeiros ao país.

Em relação à propriedade da terra, essa foi uma expectativa que se tornou realidade para imigrantes que iriam se instalar na nova colônia, ao sudoeste da Província de Buenos Aires, em territórios recentemente incorporados ao país. A região pampeana argentina passou a receber preocupação governamental, a partir da segunda metade do século XIX, para assegurar e controlar o território nacional. Para isso, precisavam ampliar a fronteira interna e estender coercitivamente os domínios sobre a sociedade indígena. Para tanto, o Governo argentino investiu em incursões militares rumo ao deserto, conhecidas como campanhas ${ }^{14}$. Nos territórios anexados no Estado-nação civilizado, foram sendo instalados gradativamente colônias de imigrantes: franceses, italianos, espanhóis, alemães.

De uma iniciativa privada, após a vitória do Governo e da "civilização," foi criada a colônia de Pigüé, em acordo com a lei de terras de 5 de outubro de 1878. ${ }^{15}$ Essa lei ficou conhecida como Concessão Plaza Montero. Com o protagonismo de três personagens: Eduardo Casey, argentino, filho de irlandeses; Clemente Cabanettes, francês do pequeno distrito de Aveyron - recém chegado ao país, em 1880; Francisco Issaly, o qual foi o agente em território francês, organizando a vinda das primeiras quarenta (40) famílias do departamento de Aveyron para o Sul de Buenos Aires, regiões com clima e atividade econômica bem parecidos. A ideia de Clemente Cabanettes era trazer seus conterrâneos para a nova colônia agrícola. Foi por meio da companhia de colonização La Curamalan, a qual tinha como sócios Casey e Cabanettes, que foi possível a efetivação da imigração. As primeiras famílias chegaram em Buenos Aires, em 04 de dezembro de 1884.

Cada família poderia receber uma concessão de 50 a 100 hectares, desde que cumprissem os seguintes critérios: " $1{ }^{\circ}$ ser cultivador, de buena vida y costumbres. $2^{\circ}$ No haber sido penado en Francia $.3^{\circ}$ Poseer un capital efectivo de três mil francos, al menos y la mitad para las concesiones de 50 hectáreas" (MONFERRAN, 1955, p.51-52). Estava criada a Colônia de Pigüé, com 160 pessoas.

Julio Huret, em uma de suas viagens, esteve no Sul de Buenos Aires e passou na colônia de aveyroneses. Ele conta que as terras abrangiam 25 mil hectares e, mais tarde, 50 mil. Para ele, era quase uma cidade francesa, com casas no estilo francês e nomes franceses estampados nos armazéns (FERNÁNDEZ, 1999, p.27).

13 Função criada pela Lei de Imigração e Colonização. Ver mais sobre a imigração e legislação comparada em, OLIVEIRA, M. D. Políticas de Imigração na Argentina no Brasil (1886-1924). Semelhanças e diferenças. Anais do XXVI Simpósio Nacional de História - ANPUH, pp. 1-17. São Paulo, 2011.

14 Era comum associar o Pampa e a Patagônia como regiões desértica, portanto, civilizar o deserto também se referia a ocupá-lo. Mas é recorrente na historiografia argentina nomear de Campanha do Deserto aquelas ocorridas na década de 1870. De acordo com Ana Pompeu, essas incursões contemplaram um plano ofensivo contra os indígenas que não se rendessem as tropas militares, expulsando-os ou submetendo-os pelas armas. Nessas ações políticas e militares, o discurso foi fundamentado na ideia da época, isto é, da civilização contra a barbárie, o que legitimava sua conduta (POMPEU, 2012, p.85). Outras investidas militares contra os índios foram denominadas como "campanhas." E a primeira delas teria sido com o Juan Manuel de Rosas, nomeado em 1833, Comandante Geral da Campanha e Chefe da Divisão Esquerda do Exército Nacional (REICHEL, 2005, p. 304).

15 Art. $4^{\circ}$. Destinase igualmente a la presente ley, el producido de las tierras públicas que la provincia ceda de la que se le adjudicará por esta ley. Esas tierras serán enajenadas en la misma forma que las nacionales sin afectar la jurisdicción provincial y los derechos adquiridos por particulares (MONFERRAN, 1955, p. 33). 


\section{UMA COOPERATIVA NO PAMPA BONAERENSE}

Os imigrantes produtores enfrentaram frequentes situações de risco e dificuldades para suprir as perdas da colheita, decorrentes das alterações climáticas, pois Pigüé está localizado na Serra de Curamalán. Um grupo se reuniu para pensar em solucionar e/ou diminuir esses problemas e dessa reunião decidiram criar a cooperativa El Progreso Agrícola de Pigüé: Sociedade Cooperativa Mútua de Seguros Agrícolas y Anezos Ltda, em 1898.

Tendemos a acreditar que esses fundadores possuíam conhecimentos prévios sobre o cooperativismo e as experiências francesas. De acordo com a primeira ata da entidade, a cooperativa foi criada para defender os interesses coletivos por meio da ajuda mútua e da cooperação. A imagem símbolo, conforme a figura 1, da sociedade, foi elaborada com um grande guarda-chuva protegendo a colheita de cereais, uma representação bem sugestiva dos seus objetivos.

Figura 1

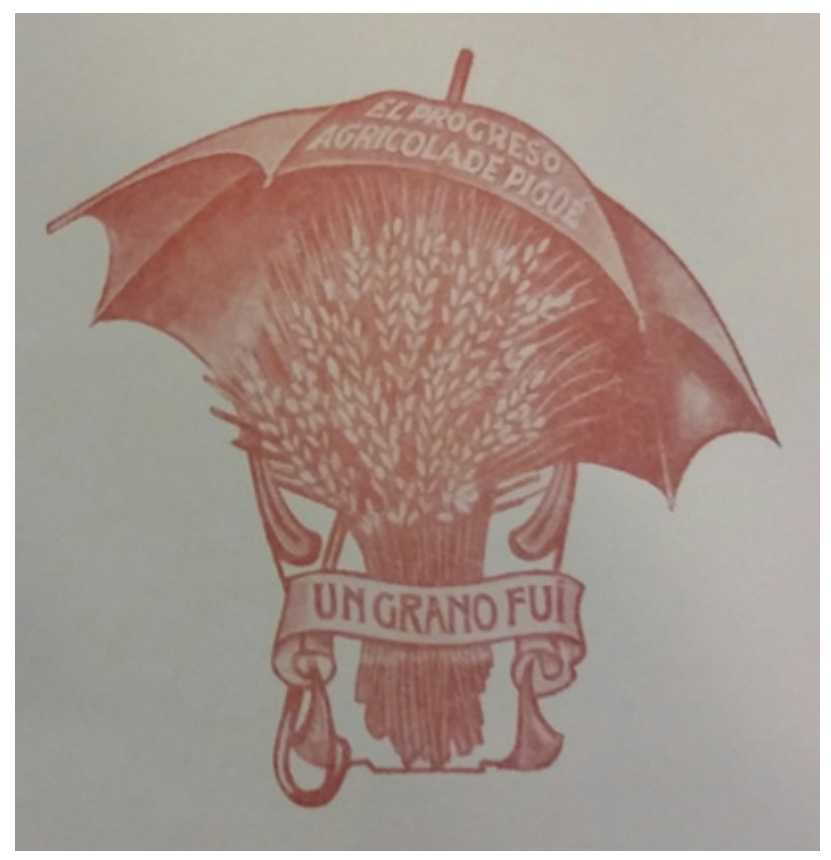

Fonte: El Progreso Agrícola de Pigüé: $75^{\circ}$ aniversario, 1898-1973. Biblioteca Utopía, Buenos Aires.

A sociedade foi fundada por cinquenta e um (51) agricultores. Destacamos Esteban Miguel Simón e Cipriano Alric, os quais iniciaram as primeiras reuniões de consulta popular sobre a possível criação de uma cooperativa. De acordo com o censo nacional de 1895, eles eram agricultores e proprietários de terra, alfabetizados, com idade entre 30-35 anos e casados. Os principais argumentos utilizados por eles para conseguirem adeptos era a prevenção dos prejuízos climáticos e a obtenção de crédito para os danos, por outro meio que não fosse o estatal. "Logo a ideia foi acolhida e recebeu o apoio do fundador da colônia Clément Cabannetes, para o então projeto sair do papel e materializar-se" (SIXTO, 1973, p. 86-87).

A concretização da ideia passou pelo acolhimento dos interessados, pois pensamos que esses haveriam de ter minimamente uma instrução escolar, levando em consideração o próprio projeto, um tanto inovador, aos finais do século XIX, numa conjuntura oligárquica e politicamente desfavorável na Argentina desses tempos. Verificamos um número significativo de alfabetizados na imigração francesa, 
de acordo com o Censo Nacional de $1895^{16}$ e de 1914..$^{17}$ Em comparação demográfica, Otero confirma que $88 \%$ dessa imigração sabia, pelo menos, ler e escrever, um resultado inferior em relação aos $100 \%$ dos imigrantes alemães e dos ingleses, mas muito próximo aos $83 \%$ dos argentinos (OTERO, 1999, p.144).

No estatuto, os fundadores deixaram claro qual seria o público de atenção da cooperativa: "formada exclusivamente por e para agricultores" (ATA de Fundação, 1898, p. 4). Ela respondia, segundo o estatuto, aos verdadeiros interesses dos produtores, cuidando de assuntos administrativos e examinando os acordos de indenização daqueles que tiveram perdas. Também era papel da cooperativa repartir anualmente o capital de sobra, afirmando-se como uma cooperativa de seguros.

Esteban Miguel Simon foi o redator da ata e dos primeiros artigos do estatuto constituinte, daquele primeiro de outubro de 1898, tudo indica que essa foi a pessoa que mais tinha conhecimento sobre 0 cooperativismo. Carlos Sixto (1973) afirma que quem contribuiu para os conhecimentos de Simon e Ihe orientou foi o economista francês Charles Gide $^{18}$, assegurando, dessa maneira, a criação de uma cooperativa de fato, e afastando qualquer possibilidade de tornar-se uma associação mutual trabalhista.

A singularidade dessa cooperativa está, portanto, na sua prestação de serviço. Em meio a agricultores, ela poderia ter sido uma cooperativa de produção ou de consumo agrária, no entanto, o seguro contra granizos era uma urgência local. Diante dos prejuízos ocasionados, foram motivados por um fator comum entre os agricultores. Justificam assim: "el seguro en todas sus manifestaciones está universalmente reconocido como de inmensa utilidade, como um gran adelanto de nuestro siglo, particularmente en la parte que se refiere a la agricultura y en la forma en que lo establece El Agrícola de Pigüé" (ATA de Fundação, 1898, p. 4).

Seus primeiros anos foram de muito crescimento e consolidação. A El Agrícola esteve em grande ascensão até 1910. Encontramos suas publicações de rotina, isto é, sobre assembleias e balanços trimestrais ou anuais, em periódicos locais; e em periódicos de departamentos vizinhos, como Bahía Blanca e Azul. Além de tornar público esses relatos úteis aos associados, o periódico (normalmente sem assinatura no texto) procurava mostrar o quão auspicioso era o exemplo da cooperativa. Para ilustrar, uma publicação no La Prensa versava sobre os avanços dos agrônomos na criação de sociedades agrícolas regionais, e afirmava que esses estavam difundindo "a boa prática" entre os agricultores. 0 mesmo texto, refere-se a El Progreso Agrícola de Pigüé como um lugar interessante de ser visitado pelos agrônomos, para que avaliassem as atividades e utilidade aos agricultores (LA PRENSA, 20/03/1910).

Mesmo depois de uma cisão no ano de 1903 - que resultou em outra cooperativa de Seguros, a União Agrícola de Pigüé -, a El Agrícola seguiu fortemente suas atividades. A notícia da divisão foi divulgada nos jornais locais, sem os motivos da separação. Os fundadores, seus familiares e outros dividiram-se entre as duas cooperativas de seguro agrícola existentes da cidade.

A El Agrícola reformulou seus estatutos por três (3) vezes desde o seu nascimento, 1901, 1903 e 1905. Mudaram a forma de operacionalizar, remunerar e assegurar direitos. Perceberam que a socie-

16 Archivo General de la Nación. Carpeta 819. "Partido de Saavedra". Segundo Censo Nacional en la Republica Argentina. Levantado em 10 de Mayo de 1895.

17 Biblioteca Central, UMdP. "Tercer Censo Nacional en la Republica Argentina". Tomo III. Levantado em $1^{\circ}$ de Junio de 1914.

18 Charles Gide foi o primeiro sistematizador da doutrina e dos princípios rochdaleanos. Professor de economia política, foi um dos fundadores da Escola de Nîmes, na França. Entendia uma cooperativa como um agrupamento de pessoas, procurando fins econômicos, sociais e educativos em comum, através de uma empresa comercial. "Em 1886, quando se instalou o II Congresso das Cooperativas de Consumo na França, na cidade de Lyon, Gide proferiu um verdadeiro discurso-programa, no qual lançou as bases da doutrina cooperativa. Em seguida, em numerosos estudos posteriores, ampliou e aprofundou os princípios doutrinários cooperativistas" (PINHO, 1965, p. 25). 
dade era extremamente local e com regras marcadamente familiares à luz de uma empresa pública que desejavam ser. ${ }^{19}$ Essas reformas frequentes podem ter ocasionado desconforto e instabilidade entre os associados, resultando na divisão de opinião e posteriormente, em duas cooperativas, em 1903.

Mas a reformulação mais significativa veio em 1914. Esse novo estatuto ampliou a região de atuação que passa a ser a província de Buenos Aires, de La Pampa e de Río Negro, com sede na cidade de Pigüé. Assegurou a liberdade dos sócios de obter novos seguros com outros empreendimentos, entre outras mudanças. Isso pode ser relacionado com a concorrência que crescia cada vez mais. Essa decisão visava, também, atrair novos associados. A El Agrícola incentivou intensamente o cooperativismo durante sua primeira década, inspirando novas cooperativas em sua localidade e em outras províncias.

Quanto à produção agrícola da região, podemos dizer que ela era bem expressiva. Segundo o balanço estatístico agrícola ${ }^{20}$ dos departamentos do Sul da província de Buenos Aires, o departamento de Gral Saavedra produzia 91.377 toneladas de trigo, em um território de 94.471 hectares, no início do século XX. Isso corresponde à zona de cobertura da El Agrícola, que fornecia seguros a produtores de cereais em geral, ficando atrás apenas do departamento de Suárez, que produzia 101.433 toneladas de trigo em 84.528 hectares. Esses dados evidenciam para nós a sua importância no cenário econômico local. Diante de uma crise com perda total, ocasionada por uma seca prolongada, como ocorreu em 1912, dificilmente a cooperativa resistiria sem ter abaladas suas estruturas. Ela resistiu, mas esse foi o ano que freou drasticamente sua ascensão.

Entre os anos de 1918-1928, a El Progreso Agrícola não viveu anos de pujança. A supressão do setor de crédito da cooperativa pelo surgimento de novas sociedades do ramo, a mudança de atividade econômica da região, de agricultor para criadores de gado; a multiplicação de cooperativas de seguro que pagavam aos intermediários comissões exorbitantes; tudo isso contribuiu para o estancamento da ascensão econômica da El Agrícola. ${ }^{21}$

A bibliografia aponta que a cooperativa de Pigüé influenciou muitas outras iniciativas, as quais uniram esforços mútuos entre trabalhadores urbanos ou agricultores, que construíram cooperativas por meio de vínculos de solidariedade. Ressaltamos que essa primeira experiência, de cooperativismo agrícola na Argentina, foi vista por alguns autores da época e escritores dos periódicos com grande orgulho. Alguns chegaram a comparar os fundadores de Pigüé aos Pioneiros de Rochdale. Os imigrantes franceses seriam aqueles que ousaram, em períodos difíceis, organizar uma entidade socioeconômica, visando ao coletivo. Uma colônia de imigrantes que alimentavam suas raízes - conforme relato de viajantes -, essencialmente católicos e produtores rurais, podem ter sido inspirados pelos pensadores socialistas franceses - precursores do cooperativismo. Isso pode ter ocorrido em maior grau do que ter, simplesmente, acatado os princípios de Rochdale.

\section{CONSIDERAÇÕES FINAIS}

Os modelos europeus trazidos pelos imigrantes são extremamente importantes, porque serviram para estruturar a cooperativa, de acordo com os princípios cooperativos, que já estavam circulando e sendo discutidos na Europa. Mas também, isso não quer dizer que houve um modelo transportado para o Sul da América. E sim, que os princípios e modos de fazer foram adaptados, em acordo com a

19 "La cooperación agrícola en Pigüé", 1916. Museo y Archivo de la Ciudad de Pigüé. Archivo Monferran: Cooperativas y sociedades (1883-1922).

20 Publicado na Revista la Agricultura, 28/01/1903.

21 Museo y Archivo de la Ciudad de Pigüé. El Orden 1934 N. Extraordinario. 50 Aniversario. Bodas de Oro de Pigüé y Arroyo Corto. "El Progreso Agrícola de Pigüé". 
necessidade socioeconômica local/ regional, o que indica a circulação cultural com a capacidade de reformulações.

As representações sociais e os conhecimentos prévios desses imigrantes, sobretudo, das experiências associativas e cooperativistas, devem ter significado, em alguma medida, a diferença na iniciativa de criar a cooperativa. Ainda mais se considerarmos a contribuição de Charles Gide nas origens da El Agrícola. Gide, no final do século XIX, era um reconhecido economista, com publicações em periódicos e participações em congressos sobre a cooperação. Nesse caso, cogitar a ideia de uma possível influência desse teórico do cooperativismo, através da presença de Esteban Simon, legitima ainda mais sua práxis cooperativa. Ademais, tal influência faz com que repensemos as interpretações que, apresentam a experiência da El Progreso Agrícola como uma associação de ajuda mútua. Quanto a isso, acreditamos que os estudos sobre a doutrina cooperativa ainda precisam avançar historicamente, os estudos de caso, locais e regionais, podem auxiliar certamente nesse esforço.

A prosperidade da jovem colônia de Pigüé era notável, conforme é evidenciado no texto do periódico El Reflector. O texto relata um pouco do desenvolvimento local e a presença de inúmeras sociedades cooperativas. Acreditamos que muito dessa prosperidade se deve a ação cooperativa iniciada com os fundadores da El Progreso Agrícola. Para o autor (desconhecido) do texto, o sucesso da colônia de Pigüé se deve a um homem, Clément Cabannetes, o qual "não precisou recorrer a nenhum tema filosófico ou utópico para tal fim" (EL REFLECTOR, 1/11/1919). É certo que a presença e atuação de Cabannetes foi importante, mas outros agentes contribuíram com isso, pois a presença de Miguel Simon e Cipriano Alric foram indispensáveis no fomento e difusão do cooperativismo.

Procuramos apontar neste ttrabalho as diferentes experiências cooperativas, desenvolvidas ao mesmo tempo. E isso nos mostra que o cooperativismo é fruto de um determinado período histórico. Muitos dos líderes cooperativos e intelectuais sequer se reconheciam, tamanha era a novidade dessa forma de organização que, simultaneamente se pretendia associação-empresa.

Na reflexão apresentada aqui, acerca de alguns momentos da trajetória da cooperativa El Progreso Agrícola, entre 1900-1920, ficamos inclinadas a pensar numa forte influência daquelas associações e cooperativas confessionais - protestantes e católicas na Europa -, as quais não deixam de ir ao encontro dos princípios de cooperação dos ingleses, no sentido de amenizar os danos do capitalismo sem negá-lo. 


\section{REFERÊNCIAS}

BOREA, D. Tercer Censo Nacional. La mutualidad y el cooperativismo en la República Argentina. Buenos Aires: Talleres J.L. Rosso y Cía, 1917.

CRACOGNA, D. O. Cooperativismo Agrario Argentino. Buenos Aires: Intercoop. Cuadernos de Cultura Cooperativa, 1968.

FERNÁNDEZ, M. I. Las inversiones francesas en la Argentina, 1880-1920. Buenos Aires: Biblos - Fundación Simón Rodríguez, 1999.

HARRES, Marluza Marques. Notas de pesquisa: Cooperativismo rural. Estudos comparados. Rio Grande do Sul e Província de Buenos Aires (1950-1970). História UNISINOS. Vol.11, n.3, p. 371-373. Set/ Dez, 2007.

IZQUIERDO, M. Y. Quince anos en el cooperativismo agrario argentino: 1953-1968. Buenos Aires: Intercoop, 1972.

MONFERRAN, E. E. Fundación de la Colonia francesa y publo de Pigüé. Buenos Aires, 1955.

OTERO, H. A imigração francesa na Argentina: uma história aberta. Em B. Fausto, Fazer América: a imigração em massa para a América Latina. São Paulo: Editora da Universidade de São Paulo, 1999, pp. 127-152.

PINHO, D. B. A doutrina cooperativa nos regimes capitalista e socialista. Suas modificações e sua utilidade. São Paulo: Livraria Pioneira Editora, 1965

POMPEU, Ana Carollina Gutierrez. A construção da Patagônia Argentina. 2012. Dissertação (Mestrado em História) -Programa de Pós-Graduação em História. Universidade de Brasília, 2012.

RAMBO, A. B. Theodor Amstad. Perspectiva Econômica. Série Cooperativismo, 35, pp. 5-47, 2000.

REICHEL, H. J. A participação dos indígenas na construção do Estado argentino (1810-1852). Projeto História, v.13, p. 295-311, 2005.

SCHNEIDER, J. O. A doutrina do Cooperativismo nos tempos atuais. A cooperação para as organizações populares. Cadernos CEDOPE. Série Cooperativismo e desenvolvimento rural e urbano, 6, pp. 7-23, 1994.

SCHNEIDER, J. O. A Doutrina do Cooperativismo: Análise do alcance, do sentido e da atualidade dos seus valores, princípios e normas nos tempos atuais. Cadernos Gestão Social, 3, 251-173, 2012.

VILCHES, L. Teoría de la imagen periodística (2ª ed.). Barcelona: Paidó, 1997.

WEISNTEIN, Barbara. Pensando a história fora da nação: a historiografia da América Latina e o viés transnacional. Revista Eletrônica da ANPHLAC. São Paulo. n. 14, 2013, p. 13-29. Disponível em: < http:// bit.ly/2iDImFa>. Acesso em: 10/05/2014. 


\section{DOCUMENTOS}

ACTA de Fundación. El Progreso Agrícola de Pigüé: Sociedade Cooperativa Mútua de Seguros Agrícolas y Anezos Ltda. 01/10/1898, p. 4. Biblioteca Utopía. Inventario n. 24716.

EL REFLECTOR, Pigüé, (1/11/1919). El cooperativismo em Pigüé. Museo y Archivo de la Ciudad de Pigüé.

LA PRENSA (cópia), (20/03/1910). Archivo Monferran: Cooperativas y sociedades (1883-1922). Museo y Archivo de la Ciudad de Pigüé.

REPÚBLICA Argentina. Segundo Censo Nacional. Levantado em 10 de Mayo de 1895. Libreto da província de Buenos Aires. Tomo 131. Tipográfico de la Penitenciaria Nacional. AGN, Carpeta 819, Cidade Autônoma de Buenos aires.

REPÚBLICA Argentina. Tercer Censo Nacional. Levantado em 1 de Junio de 1914. Libreto da província de Buenos Aires. Tomo 3. Tipográfico de la Penitenciaria Nacional. Biblioteca da UMdP, Mar del Plata, Buenos aires.

REVISTA La Agricultura, (28/01/1903). Estadística agrícola. Museo y Archivo de la Ciudad de Pigüé. Archivo Monferran: Cooperativas y sociedades (1883-1922).

SIXTO, Carlos Armero. Setenta y cinco años de la primera cooperativa agrária. Agro Nuestro, XVI, 1973, p. 86-87. Sociedad Rural Argentina. Ficheiro E5, Cooperativismo. 